\title{
CASUÍSTICA PARASITÁRIA EM CÃES E GATOS ATENDIDOS NO HOSPITAL VETERINÁRIO DE PEQUENOS ANIMAIS DA FAEF
}

\author{
CASES AND ATTENDED PARASITIC DOGS CATS IN VETERINARY HOSPITAL OF \\ SMALL ANIMALS OF FAEF
}

\author{
F. Z. ARAUJO ${ }^{1 *}$, M. F. ARABE FILHO ${ }^{1}$, Y. G. MARANGONI ${ }^{1}$, A. M. ANTONUCCI ${ }^{2}$
}

\section{RESUMO}

As parasitoses podem ser um problema de saúde pública, além de causarem sérios danos à saúde animal refletindo no aumento da rotina dos hospitais veterinários. É indispensável o uso de técnicas de reconhecimento dos parasitos visando abordar um protocolo terapêutico eficaz. Sendo assim, serão eliminados gastos com a administração de compostos químicos sem o devido efeito na população parasitária. Tais enfermidades estão intimamente relacionadas com as condições higiênico-sanitárias do animal e, desse modo, foi feito um levantamento de casos diagnosticados em cães e gatos atendidos no Hospital Veterinário de Pequenos Animais da FAEF no município de Garça - SP, no período de janeiro de 2014 a outubro de 2015. Foram diagnosticados com parasitoses dois felinos, um com Sarna Notoédrica (50\%) - Notoedris cati e outro com Sarna Sarcóptica (50\%) - Sarcoptes sp.. 39 cães, dentre eles: 7 casos $(17,94 \%)$ de Giardia sp., 10 casos $(25,64 \%)$ de Demodex sp., 2 casos $(5,12 \%)$ de Berne Dermatobia hominis, 1 caso $(2,63 \%)$ de Míase, 4 casos $(10,25 \%)$ de infestação por pulgas, 1 caso $(2,56 \%)$ de infestação por carrapato - Rhipicephalus sanguineus, 2 casos $(5,12 \%)$ de Sarna Sarcóptica Sarcoptes sp., 2 casos $(5,12 \%)$ de Toxocara sp., 1 caso $(2,56 \%)$ de Toxocaris sp., 1 caso $(2,56 \%)$ de Dipylidium sp., 5 casos (12,82\%) de Ancylostoma sp., 2 casos (5,12\%) de Cryptosporidium spp. e 1 caso $(2,56 \%)$ de oocisto de Cystoisospora sp.. Os conhecimentos das ocorrências parasitológicas são importantes para futuros estudos epidemiológicos e adoção de medidas preventivas adequadas para o combato dos parasitos encontrados.

PALAVRAS-CHAVE: DOENÇAS PARASITÁRIAS. PARASITOLOGIA. ANIMAIS DOMÉSTICOS. SANIDADE ANIMAL.

AGRADECIMENTOS: Faculdade de Ensino Superior e Formação Integral - FAEF.

ÁREA TEMÁTICA: Doenças Parasitárias. 